Article

\title{
CREATIVE SOCIALIST-FEMINIST SPACE: CREATING MOMENTS OF AGENCY AND EMANCIPATION BY STORYTELLING OUTLAWED EXPERIENCES AND RELATIONAL AESTHETIC
}

\author{
NADINE CHANGFOOT \\ Trent University, Champlain College, Department of Political Studies
}

\section{Biographical Note}

Nadine Changfoot is Associate Professor in Political Studies at Trent University, Peterborough, ON, Canada. She researches in the areas of identity, subjectivity, emancipatory possibilities within art and community organizing and their respective theoretical underpinnings. She has published in a range of areas including the performance of neoliberal citizenship as resistance, Simone de Beauvoir, Hegel, and the role of neoliberal federalism in national unity.

\begin{abstract}
This article argues that creative socialist-feminist spaces, where art-based knowledge is created, can provide opportunities for creating new knowledge with emancipatory moments for those who are marginalized and have had marginalizing experiences. In so doing, commodified existence (Hennessey 2002) becomes disrupted through the emergence of new knowledge entwined with emotion. The outcome of this kind of endeavor includes transformational knowledge of self, relations of power, and a vision of alternative possibilities in relation to that knowledge. A relational aesthetic emerges where meaning for political change is co-created through the exploration of personal experience using an arts-based medium that itself creates community and political vision. These claims are made based on personal experience creating a digital-story exploring the first memories of having a racialized body constituted by racist slurs and from a discourse that disidentifies one from Canadian citizenship and belonging.
\end{abstract}

\section{Keywords}

Socialist-feminisms; outlawed experience; relational aesthetics; emancipatory moments; digital storytelling; racialization; anti-racism; colonialism

\section{Acknowledgement}

I warmly thank Carla Rice and all involved with Project Re•Vision for their generous support of all aspects of my digital story, including my continued 
reflection upon it for personal and collective transformation. Many thanks to the anonymous reviewers and Editor for their comments and suggestions. All errors are my own.

I dream of creating a place where we can dare to be our most authentic, glorious, outrageous selves. It will be a brief vision of a possible future.

- Bonnie Klein ${ }^{1}$

Socialist-feminisms comprise diverse social, economic, cultural and political theories and practices. I imagine them forming a constellation where they co-exist with one another, intersect, and also come into tension with one another. ${ }^{2}$ Class remains an important category of analysis to socialist-feminisms, yet socialist feminists recognize that effects of power are not reducible to class (Brenner and Holmstrom 2012, 267). Additional and integral categories have been brought together and intertwined through intersectional analysis with class, including: gender, sexuality, disability, race, and colonization. As well, there is now growing recognition of the role affect emotions have in shaping social relations, self-reflection and respect for difference in socialist-feminist activism (Brenner 2014, 44). The image of a braid may be apt for this diversity and intersectionality ${ }^{3}$ within socialist-feminism; the braid provides a sense of the different, divergent trajectories (hair strands that depart from the braid), tensions, and alliances that occur and bind together (sometimes loosely, sometimes tightly) within the larger intellectual space where practices of "socialist-feminism," and debates concerning those practices, take place. ${ }^{4}$

One strand envisions and focuses on the systemic transformation of capitalism and patriarchy considered simultaneously in relation to human needs (Hartmann 1981, 1982; Mitchell 1974, 1984, Wood 1995). Another looks to greater redistribution of resources more evenly throughout society to reduce sharp income and wealth stratification produced by capitalism (Fraser 2012). ${ }^{5}$ Yet another looks at gender identities and their respective specific material conditions of discrimination and oppression to examine specific needs of women

\footnotetext{
${ }^{1}$ Bonnie Klein made this declaration at the 2008 Unruly Salon, an inaugural and groundbreaking gathering of disability culture and scholarship at University of British Columbia (accessed August 2013 at http://www.unrulysalon.com, now no longer available).

2 Albritton, Bell, and Westra note that socialism is not one thing (Albritton et. al. 2004, 4). Similarly, socialist-feminism is not one thing; socialist-feminisms comprise a multiplicity of approaches and an ongoing discussion and debate of paths forward toward better understanding oppressions and possible emancipations. ${ }^{3}$ For a concise discussion of intersectionality, see Brenner 2014, 33.

${ }^{4}$ There is also ambivalence toward the multiplicity of socialist feminist strategies informed by post-structural thought that emerged in the 1990s as a vision for politics and struggle against capitalism. See Sangster and Luxton (2012), Wood (1995).

${ }^{5}$ Fraser presents a narrative of feminism, specifically second-wave feminism as having been co-opted by neoliberalism. Sangster and Luxton argue Fraser conflates second wave feminism with liberalism at the expense of socialist-feminism, providing historical context and examples (2012).
} 
whose claims-making intersects with race, sexuality, indigenous identities, colonizing experiences (Brenner and Holstrom 2012, 283-284), as well as disability (Rice, et. al. 2016, Erevelles 2011, Oliver and Barnes 2010, Roman 2009b, Russell and Malhotra 2002). This last strand I will refer to as disability and difference from this point onward. Disability and difference recognizes diverse identities and embodiments of class, disability, gender, transgender, race, sexualities, First Nations and Indigenous Peoples, intersexed persons, and those still becoming. By using the phrase "disability and difference," I refer to and beckon identities and embodiments involving multiple and intersecting categories of analysis. ${ }^{6}$

In this article, I build upon this last strand recounting an art creation experience that attends to disability and difference. In the space of art creation, marginalized experiences can be welcomed-in; these are experiences largely rendered invisible, made unwelcome or taboo within public or private spaces. It is these very outlaw experiences (Hennessy 2002) that have been under-acknowledged within socialist-feminist theorizing and politics. To give them voice and centre them would go some way toward building a more capacious socialist-feminist practice. ${ }^{7}$ Such a space could be called creative socialist-feminist in that it is practiced and explored with the intent of fuller and fullest participation for individuals whose stories of difference have not been (or rarely) told, or heard. It could allow for the vulnerability that emerges when a hidden difference is brought into the open. "Creative" refers to art-creation or art-making that can include a variety of art mediums. In such a creative socialist-feminist space, the emergence of difference can at least begin to disrupt stereotypes produced through oppressive power. Connections among art-makers can develop via relational aesthetics (Bourriaud 2012) that become cripped ${ }^{8}$ and socialist-feminized. Stories, new knowledge, and new imaginings for better worlds emerge from the participants themselves for themselves and their communities. It is in these spaces that new senses of agency and empowerment appear, although not at the scale of system, such as the overturn of patriarchy or capitalism, but potentially at the individual and community scale. Even so, a creative socialist-feminist space is incomplete and temporary. I use my experience of digital storytelling where I decided to create a film of my childhood memories of being racialized from the outside and adult memories of more nuanced racialization, as an

\footnotetext{
${ }^{6}$ For discussion of body-becoming theory and body-becoming at the intersections of gender, race, disability, and class that bring into view the complexity of gender identities see Rice (2014).

${ }^{7}$ Ferguson (2014) and Carty (2014) engage with Luxton (2014) on this latter point in Studies in Political Economy 94. Coburn advocates participation of working class and dominated people "be taken seriously in socialist struggles" $(2014,23)$. She explicitly refers to women, disabled persons, racialized, sexual minorities, and minoritized others who are oppressed within capitalism, but not grasped well by socialisms $(2014,22-23)$. Additionally, she states "we need to actively reach out and find out what is necessary for our conversations and struggles to become relevant and accessible to the whole working class" $(2014,23)$, including those with disability and non-standard bodies and minds.

${ }^{8}$ The use of crip as a verb is inclusive of, but not exhaustive to, three meanings. To crip is to center disability and queer experiences (McRuer in Chandler 2012), to “open up desire for what disability disrupts" (Fritsch in Chandler 2012) or to enact community that desires or is motivated to dwell with disability (Chandler 2012).
} 
example. My story is an example of an outlaw experience brought into the open that also became part of a cripped and socialist-feminized relational aesthetic. The encouragement of both outlaw experiences and relational aesthetic holds potential for building upon socialist-feminist practices and knowledge.

\section{Digital Stories: Creating Space for Disability and Difference}

In Spring 2012, I made my own digital story (https://vimeo.com/120832001) which is a three to four minute self-reflexive film with Project Re•Vision. ${ }^{9}$ Project Re•Vision adopted digital storytelling from The Center for Digital Storytelling in East Bay, CA and adapted it for women living with disabilities and differences and healthcare providers. ${ }^{10}$ The workshop where I made my digital story was held in Toronto at the YWCA on Elm Street. As a participant, I discerned the highly sensitive and thoughtful efforts made to provide the broadest possible access, including wheelchair access, as well as access to those with disabilities, broadly defined. Nourishing food was sourced from a social enterprise café that employed persons living with disabilities to include physical and mental challenges. The YWCA on Elm St. was designed and built mindful of women's needs for accessibility and affordability. When it opened, the building was thought to offer the largest number of affordable housing units in the city in at least a decade. It was women-centered designed meaning it was designed for women surviving trauma and violence, living on low-incomes or living in poverty, and/or working part-time or shift work (Alphonso 2012). The Christian affiliation of the YWCA, however, would understandably be alienating for non-Christian women. ${ }^{11}$ The digital story workshop itself did not reference any religious affiliation; still, it is important to acknowledge the need to address exclusions, multifaceted aspects of Christian dominance, and the organization of creative spaces at the intersection of non-Christian faiths, disability, and difference.

The digital story workshop was a three-day temporary space where I and about fifteen diverse women in and outside the academy would each be making their digital story. It was more than a physical place to make a film. The conditions facilitated a kind of emancipation

\footnotetext{
${ }^{9}$ Self-reflexive means to reflect critically, in this instance, upon one's lived experience. "Project Re•Vision" is directed by Carla Rice, Canada Research Chair, Gender and Family Studies, also Founder of Project Re•Vision and the Revisioning Differences Mobile Media Lab (REDLAB) at the University of Guelph, ON. The project is funded by the Canadian Institutes of Health Research (CIHR). Digital story making was done in the first year, and theatre presentation of stories from women living with disabilities and differences occurred in 2014. The members of the research team are located in Law, Nursing, Critical Disability Studies, Gender and Women's Studies, Political Studies, Public Health, and Social Work. The goal of the project is to create greater equity in health for women living with disabilities and differences.

${ }^{10}$ See http://storycenter.org for more information on the history. For guidelines for digital storytelling, see Lambert (2010).

${ }^{11}$ In contrast to Canada, the YWCA in England and Wales in 2011 changed its name to Platform 51 to refer to women comprising 51 per cent of the world population (Doughty 2011).
} 
defined, here, as a reprieve from the disavowal of otherness through the very recognition and exploration of otherness through art. It created an important, yet partial, place of freedom of the kind not experienced outside the space. The creative space itself was intentionally conceived to be accessible to and welcoming of disability and difference. This space allowed for creative imagining in that it accomplished fuller aspects of participation through the temporary suspension of exclusions experienced everyday. These exclusions include but are not exhaustive to physical inaccessibility and absence of accommodations associated with physical and mental disabilities and differences. These included comfort spaces for rest and quiet, or flexibility in scheduling to a person's needs rather than an organization's needs or choices. More than this, it allowed for exploration of personal reflections that are entwined with the social, economic, and political not consistently made welcome or shared in either public or private spheres. This contrasts with most everyday spaces which exclude disabled persons and persons who do not fit normative embodiments (i.e., persons whose embodiments diverge from normative racialization, class, gender, sexuality) from the outset because the conditions for safe and full participation are absent. I acknowledge my privilege in my association with the academy; at the same time, the focus on telling stories of disability and difference allowed for my story of difference to be told in a way that I felt would "unsettle" aspects of academic privilege and open up discussions and debate on such privilege in order to disrupt it. ${ }^{12}$

The workshop became a space of safe sharing for my story of difference. Prior to the workshop, I prepared a draft of my story and discussed it with Carla Rice, Director of Project Re•Vision. ${ }^{13}$ On the first day of the workshop, I shakily shared it aloud with participants in what was called a storycircle. After the storycircle, time was given to work on it some more. In the quiet time where revisions were made, I realized I harboured a foundational desire and identity to feel myself fully-belonging Canadian in ways that exceed legal citizenship. During childhood, I had experienced loss and shame from being denied that very identity and belonging. I felt a palpable risk in telling my story: having been denied being Canadian, I feared reliving the shame and loss, and again, being denied. I was uncertain how my story would be received in the workshop especially since, aside from Rice, I had no or very little prior connection with the participants. And, while I had previously met with some individuals in the workshop, I had not shared my story that was personally threatening to my

\footnotetext{
${ }^{12}$ Bannerji et. al. note the importance of telling stories that rarely get voiced in the academy to be taken seriously in academic debates $(1992,5)$. Indeed, they point out that the organization of power and knowledge in the university makes it possible not to reflect upon class, gender, race $(1992,7)$; the conferral of dominant normative power relations within the academy becomes the silent norm. Ng describes the silent and invisibly embedded systems of sexism and racism in the university and how they become brusquely visible in a student complaint while sexism and inequality due to race, class, gender, ability, sexuality reinscribe themselves through university language of "neutrality" (1993, 196-198).

${ }^{13}$ Carla Rice's supportive attention to my story made it a better story. I found the courage to tell it from her enthusiasm and encouragement.
} 
sense of belonging.

I realized that disclosing my story created vulnerability on my part from the threat I experienced in sharing it. Yet, I continued because I wanted to tell this story to better understand my own experience of racialization and racial discrimination and my perceived personal inadequacies I associated with these experiences as a young child. I understood that the workshop had been designed as a safe environment and that motivated me to choose and tell this story. The workshop facilitators said they were committed to hearing stories of disability and difference. I decided to trust.

\section{Outlawed Experiences}

The workshop took seriously outlawed experiences (Hennessy 2002, 85). According to Hennessy, "under capitalism, human affective and sensate capacities have been produced such that some ways of organizing them are consolidated into legitimate "experiences" and social relations while others have been outlawed" $(2002,85)$. This concept of "outlawed experiences" provides a conceptual opening toward theorizing the experience of digital storytelling in an overarching or broader context of commodification.

Commodification transforms human beings and living entities into exchange values: human beings become objects each with a price tag that makes invisible social costs borne by society and surplus value appropriated by capital. ${ }^{14}$ In the conversion of human beings to exchange value outlawed experiences of emotion go unrecognized as having value and indeed become devalued. These include the pain and suffering related to oppressions from poverty, abuse, disability, mental illness, homophobia, racism, etc., and their intersections. These emotions and the experiences from which they arise can become marginalized, delegitimated, and/or abject. In my own case, I have marginalized my own experiences of racialization and racism because there is pressure to keep such experiences private and hidden from view. I have dismissed and delegitimated my own emotions related to racialization in order to maintain a degree of intelligibility I felt necessary for myself in each instance of being excluded from the Canadian body politic. If I was not recognized as belonging Canadian, I pursued other qualifications I perceived legitimate such as through the education system. ${ }^{15}$ I came to understand my abjection of my ethnicity and skin colour

\footnotetext{
${ }^{14}$ Not to mention the exclusion of one's own unique individuality that becomes eliminated through commodification (Marx, 1988 (1844)).

${ }^{15}$ Yet, the recent Macleans cover story “Too Asian” (Findlay and Kohler 2010) reveals continued racialization and racism in reference to "Asian" and "Canadian" embodiments, norms and standards around post-secondary education whereby studious high-achieving "Asian" students are putatively having a negative (including killjoy) impact on the university experience for white students. I place "Asian" and "Canadian" in quotations to denote that Findlay and Kohler's deployment of these words are controversial for their racializing and racist effects. For critique of the "Too Asian" controversy that erupted from the Macleans article, see Bhandar, Gilmour, Jeer, and Ma (2012).
} 
partially reflected my desire and performance of acceptable embodiments in work and play. Sefa Dei et. al, sum up concisely that the articulation of White hegemonic power denies and silences the experiential realities of bodies of colour (2010, xii). Such experiences are legitimate only as zones of exception ${ }^{16}$ in which they should not be spoken, seen or made intelligible lest they bring harm, injure or destabilize the existing order, or "infect" the body politic. Indeed, socialism has been suspect in this disavowal of bodily experience, arguing that women's experiences of racism or homophobia, for instance, are essentially secondary systems of oppression to that of class. ${ }^{17}$ Following from Hennessey, these regulative norms fracture our human capacities "as affective, sensuous, social beings" $(2002,85)$. They exact enormous social costs largely borne privately by individuals.

At the same time, there are many experiences of emotion that are valuable to commodity exchange, legitimated, and considered desirable. These would include emotions of triumph over adversity, perseverance, tenacity, and courage that have culminated in already valued goals that resonate with dreams of the middle class, the corporate elite, or celebrities. One can or can have struggled with class (understood in the mainstream as living with hardships associated with low income or poverty), discrimination (at the intersections of class, race, sexuality, disability, for example), however, present hardships and struggles will be temporary and at a future point, definitively relegated to one's past, not to be repeated; or, if repeated, once again overcome or managed. Oprah continues to grow her brand based on this kind of narrative. Her stated intention is to empower girls and women by celebrating the individual overcoming of class deprivation, racism, homophobia and disability through personal perseverance. ${ }^{18}$ Roman refers to this kind of overcoming as "productivist notions of productivity." They place responsibility on individuals for their overcoming and success, assuming that individuals are fully empowered at the outset to do so $(2009 \mathrm{~b}, 685)$. This abstracts individuals from their social, cultural, and economic relations of oppression, that in turn, deny the role of collective struggle in bringing about social transformation. ${ }^{19}$ Denial can also occur paradoxically through the coercive aspects of compelled self-disclosure, and repetitive disclosure (Roman 2009, 684). Speaking from a context of disability, Roman explains that persons with invisible disabilities are compelled by able-bodied persons to explain their disabilities over and over because they are not readily readable on the body, suggesting that disability needs to be visible, for example, through a wheelchair or

\footnotetext{
${ }^{16}$ Giorgio Agamben (2005) uses this term for spaces created by the state where persons become deemed legal exceptions and dwell invisibly without claim to rights and law, and under conditions of violence and deprivation.

${ }^{17}$ Coburn discusses the effect that adherence to class as the primary system of oppression has on considerations of lived experience and intersectionality $(2014,4-6)$

${ }^{18}$ For discussion on how the Oprah Effect (Oprah's self-belief and success) overcomes adversity see Janice Peck (2013).

${ }^{19}$ See also, Roman 1988, 2004; Ferri 2008; Taylor 2004; Ware 2002.
} 
non-normative embodiment such as asymmetric embodiments, for and answerable to able-bodied society and repeatedly for the able-bodied (2009b, 684-686).

Hennessy does not discuss these kinds of experiences, however, she notes that labour power as something "owned" by a person emerges only when her human potential is severed from her very being. Her human potential for work to become the fullest person possible must be suppressed to become exchange labour. It is only in this way that she can commodify her capacities and even her personality into a thing that she can sell $(2002,85)$. Alienated human potential under conditions of exchange labour cannot be expressed imaginatively in the fullest sense possible where human fulfillment is the goal. For women, their respective needs largely become subsumed, silenced, and subordinated to the commodification process that is premised upon a history of masculine, patriarchal, racialized, sexualized, class, able-bodied, and gender norms and practices manifest in myriad and complex ways.

One way to bring to light the depth of these (un)acknowledged experiences is to create spaces to encourage their expression in ways conceived more creatively and more broadly. Commodified labour renders valueless what it would consider unproductive sensate experiences; in doing so, individual expression becomes repressed and unacknowledged from the full potential of human capacities. A socialist-feminist ethos that encourages and allows these to come forth presents an opportunity to explore the knowledge in the sensate's initial release as an end in itself, understanding this sensate experience itself as integral to what it means to be fully human, to be further explored alongside or within socialist-feminist goals. This is different from an approach that views or assumes emotions useful only insofar as they serve the assumed ends of socialist-feminist goals for socialist transformation. But, as noted above, this excludes too many.

\section{My Outlawed Experience}

My own outlawed experience involves coming to awareness of my racialized embodiment and certain experiences of racism. ${ }^{20} \mathrm{I}$ had begun to realize at the beginning of Project Re•Vision that powerful emotions were surfacing more regularly in discussions of difference relating to specific childhood experiences. I was becoming more aware of their reverberations in adulthood. I anticipated that putting my reflections into the digital story might be beneficial for my own emotional health, self-acceptance, and strengthening of my capacities in my own communities. I was optimistic that working through the experience of difference relating to my racialized embodiment, I might also experience new possibilities for agency. It was a process of both self-development in terms of personal exploration, and becoming more aware of human affective and sensate capacities in Hennessey's words.

\footnotetext{
${ }^{20}$ During the making of my digital story, I came to awareness that this was not my only outlaw experience. The making of this digital story is (en)couraging me to theorize the intersection of disability and difference in ways I do not yet fully understand.
} 
Powerful and threatening emotions arose when I started to describe in words my childhood memory. They were powerful in that I felt thundering tremors coursing through my body; I nervously jumped and cowered inside responding to the thunder as if it were booming directly over me. The memory of racist slurs were verbal shots fired at me by an assault weapon and I braced my body in preparation for their contact. They lodged into my flesh at all points with my insides exploding in vulnerability and pain. The emotions felt threatening because I remembered the desolate isolation and stopped-in-my tracks confusion of not knowing what to do, whom to tell, or what to say, and seeing the destruction of my identity as Canadian and friendships. I remember simply falling apart inside, trying to maintain an air of indifference on the outside, or saying something mean in retort which only invited more of the same racial slurs. In preparing my story, I felt I was re-living my childhood experiences.

I had not shared previously that I hated my body as a child. I accepted the racial slurs; I thought my body was abnormal and deeply shameful in appearance in comparison to the silent and desired body of whiteness. I neither belonged nor was I Canadian because I had the wrong body. I felt very vulnerable at this realization; I found myself powerfully feeling the shame and self-hatred as if it were happening all over again in the present.

I also remembered the source of the remarks. They came from childhood girlfriends with whom I had come to feel a sense of togetherness that was cozy and secure. The feeling of friendship was of us wrapped in a warm secure blanket. Then, the taunts aggressively ripped the covers off.

"Yellow skin." "Slanty eyes." "Flat nose." "Chink." Taunting sounds mimicking an imagined Chinese dialect. Repeat loudly and louder in what would feel like endless time.

Suddenly, with these sharp words and sounds directed at me, I felt a blunt knife severing me from the feeling of togetherness and belonging. Unfamiliar bodily differences I had not heard prior ("yellow skin," "slanty eyes," "flat nose," "chink") differentiated from the implicit white body was imposed on me in a way that I had no control over and did not fully understand, by my closest friends, no less. I felt my difference was of my own doing, something innate, because it was my body they were verbally shaming and severing.

I blamed myself for not having the right body; I did not understand I was being marked different by those who did not need to mark themselves. In those tense and anguished moments, they spoke from a position of power. But I was eight years old at the time and what did I know, except what I was feeling? Yet, my feelings, too, were outlawed by my own censorship because of the need I felt to be problem-free and impervious to the racial slurs and taunts for my parents and teachers. The loss I felt most acutely was of a happy, joyful, flowing mind-body movement of existence where mind and body were not separate: mindbody flowed as one. I did not question or see my body as a racialized body until it was declared from the outside as a raced body, as the foreigner, the other, the one who did not belong, the visible 
abject.

As a child, I was also routinely asked "the question" of origin, "Where are you from?" with the refusal to acknowledge or accept that I was from "here." Additionally, the way in which the question was asked had a tone of policing and judging, and convicting all at once. During those moments, I would grip my insides so tight, hoping, praying, willing as hard as I could for the questioning and conviction of not belonging, of not being from here, to end. And yet, when it did end, I felt disoriented. My sense of who I was, my citizenship and nationality were unsettled and confused; I felt dislocated from the outside. I was born here. "But, (even if you were born, here) your parents weren't!" This signaled my not truly belonging, not truly Canadian-ness in ways identified by Himani Bannerji (2007). My immigrant parents were also racialized and identified as outsiders (even though they were well on their way to citizenship) and their identity as outsiders trumped my birthplace. My hopeful reply of "but, ...", with explanations of the process of parents' permanent residency and their being on the path to citizenship as my evidence of belonging were met with dismissive intoned and intended exclusion. This dismissal of my evidence confirmed for me the sense of not belonging, of not being Canadian completely or properly enough.

I came away from these "dis-identification sessions" feeling cast-out by my closest friends, my then peer-group. I kept these experiences from my newcomer parents for fear that I was responsible for this treatment. The feeling and fear of not-belonging is one of the emotions that reverberated throughout my childhood and into adulthood. My sense of belonging in Canada as a true citizen would be rendered fragile by the repeated question: "where are you from?" followed by, "no, where are you really from?" to my answer of "Sarnia, Ontario." The question " where are you from?" was a discourse of exclusion and othering; there was an expectation for an answer of birthplace outside Canada in tacit comparison to the questioner's own claim of inclusion and belonging as Canadian. And, when the answer of homeplace was within Canada, a place outside of Canada was found for me by substituting my newcomer parents' birth country. ${ }^{21}$

There was at work in this angle of questioning a sharp dis-identifying process of the subject from my own self-understanding in terms of legal status, and social and cultural standing as citizen within my locality and nation. The question "where are you from," continues as an adult. I now sometimes reply with the question whether they are asking after my ethnicity and/or the ethnicities of my parents, and after answering, I ask "and how about you?" I sometimes edit the question depending on the circumstances to ask: "Where is your hometown or homeplace?" "What is your ethnicity?" "What generation are you," with the always implicit phrase, "in our country Canada, also a white settler nation."

In addition to these memories and emotions that arose during the workshop, I also found myself managing the memories and strong feelings of being made an outsider and felt fearful of rejection by the peer group at hand who were also making their own digital stories.

${ }^{21}$ My parents' birth country was South Africa. They left South Africa to leave apartheid. 
I knew I was in a supportive environment, yet still, I was acutely aware I was the only one in the workshop making a film about racialized embodiment and I felt it was risky to share the point in my life where I realized this difference was marked from the outside. I felt internal shaking and anxiety over the response to my story, particularly non-acceptance, or worse, indifference.

Finally, I felt shame of my own shame. Larocque's (2010) account of First Nations' lived experience refers to this double shaming. She writes that Indigenous peoples experience living "shrouded in shame twice over: racial shame and, to the extent we may be conscious, shame about feeling ashamed" $(2010,121)$. She notes the internalization of the colonizer's images of the "grotesque, ignoble savage is perhaps the most damaging" $(2010,121)$. In my own case, I realize that one part of my lived experience was constituted by the injunction of my racialized otherness made concrete through the slanty-eyed, flat nose, yellow-skinned, chink stereotype. When combined with economic privilege and knowledge available through critical race studies and feminism, as well as my experience in community advocacy as a leader of a Community Race Relations Committee, I also wondered "shouldn't I be over this vulnerability, shame, feeling of abjection, and uncertainty of belonging?" While some might answer, "yes," Larocque draws on Puxley to say that "a lengthy colonial experience deprives people of their right to define their experience authentically, but even deprives them of consciousness of such a right" $(2010,121)$. This colonial experience resonates: I had been internalizing the shame and its outlaw dimension helped keep it intact.

One of my fears in making my digital story was that I should have been able to be strong enough at some point between these childhood experiences and the making of the film to have come to an adequate understanding of what happened to me with an accompanying theorization. Larocque's concept of "shame twice over" offers how this expectation is unrealistic yet understandable. It was within the reassurances of a safe space of the workshop that I decided to tell my story in the presence of fear and the secret shame over having a racialized body, of having been excluded because of it, for not knowing how to stand up for myself, for not knowing how to respond to the explicit racial slurs of childhood and more subtle othering as an adult. There were many points during the making of my film where I just wanted to bury my head in the sand and disappear from the world. The difference was that people in the workshop wanted to hear my story and were able to witness its telling in a way I had not previously experienced. What was new was an acknowledgement that what I had experienced was very real to me and that the experience was something that happened which would not occur in another world where anti-racism would be valued and practiced. ${ }^{22}$ In

\footnotetext{
22 The ongoing critical reflection and practice of anti-racism, compared to the elimination of racism is an important distinction. George J Sefa Dei et. al., discuss how it is that anti-racism is an ongoing project. Victories against racism can be regulated, "re-tooled" or "re-focused" by racism in ways that blunt the apparent gains (Sefa Dei, et. al. 2007, 5). Sefa Dei et. al. suggest that it is in providing tools and perspectives for the oppressed to write and re-write their constitution within oppressive and interlocking frameworks of racism, sexism, heteronormativity, and so on that new possibilities for resistance, insurgency, and social change may be
} 
retrospect, I felt safe enough within the creative space to be vulnerable among my fellow participants.

Feminist anthropologist Ruth Behar (1996) speaks of the value of this experience. For Behar, new and important knowledge emerges when researchers make themselves vulnerable with an openness and honesty for critical purpose $(1996,14) \cdot{ }^{23}$ Following this line of thinking, when a person allows herself to become vulnerable with others an interruption of norms can occur, provoking personal and collective transformation (Rice 2015, Rice et. al., 2016). A fellow participant working in education approached me and shared that my story was still highly relevant because children continue to perpetrate and be the objects of racist slurs. She shared that my story would likely have meaning for children and educators. ${ }^{24}$ The response to and support for my story in the workshop, gave me the courage to theorize my story as an outlawed experience.

\section{Relational Aesthetics: Political Possibility from the Ground of Vulnerability}

Each storyteller shared their story of disability and/or difference. In hearing the stories, what confronted me especially were the stereotypes and misrepresentations circulating within society of those living with disabilities and differences. These stereotypes did not fit with the women's stories being told; I was challenged by the "gaps" between the stereotypes and the diverse and rich realities of lived experiences of those living with disabilities and difference. For example, there was the image of a beautiful young woman exuding self-confidence in photos bespeaking the 1960s who the workshop audience learns is violently abused by her husband, institutionalized, released, and eventually dies on the streets, homeless, estranged from her family. The storyteller is the grand-daughter seeking to make sense of what happened amidst the silence within her family. In another story, a young woman with a nonstandard body defies medicalization of her body, invites, indeed dares, her viewer to continue to fix their gaze on her naked body and see all of her while different images of her naked body flow across the screen, giving her viewers entrance into her rich, artful world while at the same time resisting the medicalization of her physical appearance by remaining silent about it. The stories and the films themselves had the effect of disintegrating certain stereotypes and misrepresentations in a way different from scholarship in that the outlawed experiences brought to light created a relational aesthetics that I will discuss next.

Relational aesthetics that becomes cripped and socialist-feminized involves

possible, in contrast to providing answers to the end of racism or any oppressive system $(2007,10)$.

${ }^{23}$ Behar makes clear that a person's vulnerability even when expressed in the description of emotion and/or emotional needs must become subject for discussion in service of a critical purpose or direction, otherwise, it becomes focused on that person's suffering and brings critical thought to a halt.

${ }^{24}$ For elementary school interventions in anti-racism see Roman and Stanley (1997); Roman and Eyre (1997). Reframe Peterborough International Film Festival announced in 2015 its plans to screen my film in its Reel Kids school program in 2016. 
co-creating meaning within a creative space where there is awareness of multiple and intersecting oppressions and support, empathy, compassion, an openness to vulnerability, group discussion and spontaneous conversations among participants. Relational aesthetics comes from Nicolas Bourriaud who resisted the view that art of the 1990s was surface consumerist art and depoliticized. Bourriaud argues that relational aesthetics arises from art itself being a social space where the possibility of intersubjective encounters occur over meaning, not only about the art, but also the referents those encountering the art together bring to light collectively with one another (2002, 16-17). For Bourriaud, "relational aesthetics" arises from art itself because art "creates free area and time spans whose rhythm contrasts with those structuring everyday life" $(2002,16)$. When cripped and socialist-feminized, these free areas and time spans provide a release from the oppression of capitalist time, welcoming-in experiences kept hidden and suppressed in a new time-space that strives to be open to the lived experiences of disability and difference. Encounters between persons occur through art that would not occur otherwise because our communication and interactions with one another are so highly regulated.

I assumed prior to the workshop that the experience of making the digital story would be largely an individual and private one. Yes, I was going to be making art within a group of women and I anticipated the journey would be an emotional one given the subject matter and experiences. However, the co-creation of knowledge was something I did not anticipate to the degree experienced. The depth of lived experience and the accompanying emotional journey transmitted by each story was enormous. Outlawed experiences and emotions within the daily existence of commodification had been allowed to surface, indeed encouraged, to be told, and shared. The conditions of the workshop created a safespace for participants to be vulnerable with each other. At the same time, the participants actively created a supportive, cooperative place where we could learn together. In so doing, new encounters occurred with a sense of deeper understanding of the very wide range of experiences living with disability and difference brought to the space. This was enlivening because stereotypes of disability and difference became clearer, and the conversations that occurred around the stories and films opened up new ways of thinking and acting outside the scripts that follow or assume the stereotypes.

Bourriaud likens the encounters with art to the back and forth in a game of tennis: there is a serve and a return, implying continued exchange with a willing partner. Bourriaud implies a transformation from competition to collaborative and cooperative communication and I observed it can become a cripped and socialist-feminized space of relational aesthetic. In the workshop, I discovered meaning was created in encounters during the making of my digital story. I shared my deliberations over visuals that would convey the feeling and experience of being "outsider" in Canada; symbols and objects came up independently and simultaneously. With one storyteller, there was a shared recognition in the form of laughter in acknowledgement of the Queen of England and the Canadian National Anthem that I would eventually use in my film as emblematic of official Canadian identity and sense of 
belonging.

I was also able to discuss with some storytellers at a much greater level of detail the racialized meaning of a portrait given to me as an adult by a young girl where my skin was represented with bright yellow and described by the girl's parent as physically accurate of my skin tone. I recall physically cringing, feeling pain, and unable to say anything that addressed the remark upon hearing it. There was discussion following this that explored the meaning of skin tones as markers of race and ethnicity and how skin tones can still connect to racial slurs and stereotypes. Initially, some fellow participants thought the portrait sweet and a very kind gesture. When I offered that the portrait was also a form of racialization and reinforcement of the stereotyped Chinese yellow skin colour and slanty eyes, there was recognition and acknowledgement of the complex role of racial-cultural stereotypes and their normalization. ${ }^{25}$

For me, this was a "tiny revolution" where there was some greater clarity about the racialization of representations of Chinese ethnicity. I felt a different future might be possible where stereotyped representations of skin colour, slanty eyes, and otherness were concerned, "pointing to a desired world, which the beholder thus becomes capable of discussing, and based on which his [her] own desire can rebound" (Bourriaud 2002, 23). At the very least, I felt that within the community of storytellers, something additional had been created: the realization that the deep appreciation of a child for an adult in a portrait can also carry complex histories of racial stereotypes that remain naturalized, if not addressed. It was within this space of the workshop that exchange over my digital story created a relational aesthetics with emancipatory capacity in that the space also became a forum for discussion beyond the object produced (Bourriaud 2006, 20).

The social change I imagined from the experience was important, even if it was an imagined reality that I was glimpsing in my exchanges with the women in the workshop. Bourriaud anticipates the emergence of a horizon, "a desired future or world which the exchange will reveal in discussion" $(2002,23)$. Indeed, I imagined the possible interventions that would potentially have made a difference for myself. For example, feeling safe to approach parents, a friend, or teacher at school to alert when racial slurs occur; to express how racial slurs are hurtful; feeling confident that racial slurs are clearly unacceptable; having confidence teachers will make effective anti-racist interventions, something not yet assured.

More broadly, utterances were made in the workshop, imagining a world where the pain, suffering, indignities, discrimination, marginalization, criminalization, exclusion, and violence arising from the universalization and dominance of abled-bodied norms, norms of whiteness, heteronormativity, and patriarchy would be chastened and yielded. What was absent from the everyday was brought into focus. For example, racialized and non-normative bodies are socially made or constituted and marginalized through norms of whiteness and able-bodiedness (Davis 2013, Erevelles 2011, Colin and Barnes 2010, Bannerji 2007, Russell

\footnotetext{
${ }^{25}$ For discussion on normalization of stereotypes as common sense, see $\mathrm{Ng}(1993,193-196)$.
} 
and Molhotra 2002). That this could become central for consideration, even if only ephemerally, was itself emancipatory in that such a collective consideration is outlawed from daily experience.

One critical observation made of relational aesthetics by Claire Bishop is an anxiety that it can "collapse into compensatory (and self-congratulatory) entertainment" $(2010,79)$, and I will add within a feel-good frame, perhaps even a self-satisfactory "look-at-me, I'm so great" moment. However, when embodiments have been marginalized, abjected, or minimized through colonization, ableism, heteronormativity, and so on, the emergence of new representations need to be given time and space to allow their disruptive effects as resistance to unfold and take hold. This could be understood as an inverse contrapuntal reading, following Larocque's position to "foreground Native responses to centuries of misrepresentation" $(2010,12)$ rather than criticize them according to traditions of western criticism that she notes can be aggressive and ruthless. Larocque notes that both the creation of Aboriginal material and literary criticism of it represent new bodies of knowledge that distinguish themselves from western literary traditions. Extending Larocque, creations of art and knowledge from the margins and abject deserve time and space to live in recognition of the work as resistance and the struggle for the work to come to representation. When thought of as newly emerging, new representations from the margins deserve consideration from whence they came. New representations would become weakened, if their purpose exclusively remains to be affirmed. When the work is animated by desire for social justice, the goals of the work aim at self-reflexivity in ways that include awareness of new stereotypes or reinforcement of familiar ones.

A sense of achievement in creating and learning something new about oneself was an ephemeral moment in the making of my digital story. Yes, there was a sense of a job done well-enough with accompanying "I would have done that differently," having learned and created something new, being opened up to new experiences, including the dark knowledge of those living at the margins whose lives ended because they were not considered worthy of life. However, any trace of accomplishment approaching self-congratulation became quickly revised by the ephemerality of the space as well as the density and magnitude of system change and intersubjective change required for the otherness recounted in the digital-stories to be meaningfully addressed, let alone the accompanying economic transformation required. Among the dreams and goals of disabled persons is to earn a living wage in meaningful employment and to participate fully and be recognized as fully participating in society (Wendell 2013, Shier et. al. 2009, Wilson-Kovacs 2008). The creative socialist-feminist space of the workshop was recognized as one part of a broader strategy to facilitate change in meaning and structure of employment: not simply inclusion into the capitalist labour market on its on terms, but a working place or space where all human beings, including those non-normatively different and disabled, experience life as full/er self-expression rather than alienation. Seeds were planted to imagine work and play spaces accessible for different, non-standard, non-normative bodies in ways similar to the 
storytelling workshop. As well, there were imagined transformations of work and play spaces into places of human sharing rather than places where surplus value and profit are created and appropriated by the capitalist. The digital story filmmaking provided a space where imagined change became clearer from women's experiences themselves and how these experiences need to be translated to employment for persons living with disability and difference - and ultimately, into very different ideas about human labour, with human labour that would no longer be commodified at the horizon.

The relational aesthetics within the space came to an end after three days and with it so did the safe haven where otherness and outlawed emotion were welcomed-in. At the end, reality flooded into the space and we all had to leave. Along with my fellow digital-story filmmakers, I felt roughly grabbed back with jolts disrupting a comfortable rhythm established over the three days into my own current of activity. I felt so much was on the cusp of changing in my own self-understanding; my past had shifted and in having my story shown and having seen others' digital-stories, I felt a sense of empathetic acceptance with the desire and capacity to embrace others who shared this journey. I was ready, too, for a different dialogue over the experiences of marginalization, violence, trauma, and abjection intertwined with disability and difference: not one exclusively of consciousness-raising, but one also of making clear where experiences under discussion do not "mesh-up" into and resist a totalizing logic of oppression and singular solution. The diversity of experiences, instead, created ripped edges of understanding that did not resolve into a unity or coherence of sorts, but instead coaxed a capacity for acknowledgement of the complexity of multiple and intersecting oppressions involving gender, class, race, sexualities, abilities, and colonialism.

As a temporary community that came into connection intimately for three days, the memory of the relational aesthetics, of artful relating and relating artfully, continues to be a powerful memory and inspiration for further action. The relations within the workshop enacted democratic principles of consensus, intense listening, support, agency, and arguably an emerging principle of vulnerability, however, they were immanent to the space of the workshop. There was no debate or dialogue over specific political, social or economic program for change and how the group would be part of that transformation. Nonetheless, one knew that the stories and films would be shared in future spaces specific to each participant's communities. ${ }^{26}$

As well, there were socialist-feminist visions of full access to participation and individual economic and social needs being fully met according to one's abilities. These conditions were not put into words or a program-of-action, rather, it came into tangible existence as a present-absence from the stories themselves. The future was felt in the negative spaces, in the interstices, created by the stories that showed implicitly what should not and

\footnotetext{
${ }^{26}$ Each digital storyteller owns their film to do with as they choose. Project Re $\bullet$ Vision provided each storyteller options whether their film would or would not be screened publicly for research purposes. My film was accepted and screened at the 2015 Reframe Peterborough International Film Festival.
} 
need not have happened in terms of the range of marginalization, indignities, exclusions, and violence storytellers experienced. For myself, the racialization of the body rendered other and not belonging was an act, an incident from which to learn the complexities of otherness and belonging for their acceptance and allow for diverse visions of belonging and anti-racism. At the end of the workshop, there was an ongoing anger and frustration toward the relations of power that create and maintain multiple and intersecting oppressions, as well as a loss for what the workshop provided: the resources of space and time to reflect upon these power relations and connection with others. ${ }^{27}$ There was also recognition that transformation at the local is an ongoing process and that the workshop could be viewed as part of an iterative process.

\section{Creative Socialist-Feminist Spaces: Diverse Socialist-Feminist Strategy}

To conclude, I have presented some of my experiences as participant in the creation of a recently developed arts medium, the digital story. In the space of creation sensitive to and welcoming of disability and difference, that is, a space that is cripped and socialist-feminized, I found the following are encouraged and facilitated: sensate experiences and needs outlawed by commodification are allowed to surface and dwell more openly for a temporary period in a safe and comfortable environment with fellow travelers going through the same experience. A relational aesthetic emerges where meaning is co-created through intersubjective exploration; and future trajectories become imagined where women who have made digital stories can continue to screen their films and disseminate knowledge from the project.

The creative socialist-feminist space I experienced, offered opportunity for both dis-identification from stereotypes and new possibilities of identity-formation and agency. Importantly, this space welcomed-in emotion inseparable from outlawed experiences, and emotions were given words and acknowledged. In contrast, these emotions and outlawed experiences are largely unwelcome and disallowed within commodity capitalism because a person must commodify herself as labour power and suppress her experience as a fully sensing and emotional human being. For me, the powerful emotions in response to racism and othering of my body from Canadian belonging and social citizenship were given words in a space that welcomed them for the first time. From my experience, I suggest that a creative socialist-feminist space has the potential for persons to share, make visible and individually and cooperatively explore and make meaning of outlawed experiences relating to gender, class, race, disability, colonialism, and sexuality even if only temporarily. Given the vulnerability involved in bringing these outlawed experiences into the open,

\footnotetext{
${ }^{27}$ Perhaps the need to mark the end of emancipatory timespaces is important. Anderson asked the question of the need to eulogize the end of The Unruly Salon series, inaugural performance spaces for disability artists held at the University of British Columbia in 2008 (Roman 2009, 672). While there was celebration and pride for these important salons, there was also grief and a sense of finality to their ending, as well as knowing the importance of continued work in creating spaces and opportunities for disability artists.
} 
socialist-feminist principles are vital in these creative spaces. These principles importantly relate to material comfort, allowing for safe spaces of intense expression, negotiation, listening, respect, vulnerability, accessibility and inclusion in ways not experienced outside the space. As well, the limitations of this space are several: the space was temporary; while the project aimed for the greatest diversity possible of participants in the workshop I found that in the workshop I attended, I was the one visible Asian woman, yet also privileged in class, sexuality, and appearance of the able "mind and body. ${ }^{28}$ I centered racialized difference in my digital story film. In being able to reflect upon and express experiences relating to racialization, I began to recognize more profoundly the stakes of maintaining and making clear the distinction between racialized embodiment and the standard able mind-body. Even while my body was pointedly excluded from Canadian-ness as a child, and subtley so as an adult that continues now, my keeping my outlawed experience under wraps gave me the illusion that if I did not refer to these instances of exclusion, I could rely on, feature, present, or perform the parts of me that were acceptable and fit into the mind-body exigencies of any given ablebodied-demanding location. Recognizing these stakes may lead me to another film or art-making having to do with outlaw experience at the intersection of racialization and normative able-bodiedness.

The intertwined processes of self-reflection and art-making inadvertently also became the facilitation and encouragement of a space for a relational aesthetics. This kind of space supported honest exploration amid vulnerability in bringing forth new knowledge created collectively through spontaneous discussion, not in a systematized or systematizing way. The knowledge created was highly valued in the context of building equity because the lived experience and needs of women living with disabilities and differences is extraordinarily devalued within a society that privileges abled-bodiedness and disavows physical, mental, racialized, colonialized differences, reducing them to inferiority or rendering them invisible, unintelligible, or abject. The knowledge also has a fragile quality in that a person who decides to bring to light what has been shamed and deemed worthy of only being hidden makes themselves extremely vulnerable in terms of their own self-identity and sense of worth as a person in relation to dominant norms. I also discerned strength for having brought forth these buried experiences for their dissembling effect of racist stereotypes in my own case as well as a reassembling from the political insights brought to light. A relational aesthetic within a creative space appears to create possibilities of agency, connection and interventions that carry forward beyond the space itself. Politically, these creative spaces strike me as important for socialist-feminisms to consider as part of a broader and diverse socialist-feminist strategy.

\footnotetext{
28 There are challenges regarding the recruitment of women of color and Aboriginal women and their intersections with class. See Castledon and Garvin 2008; Meadows et. al. 2003, 4-7.
} 


\section{References Cited}

Agamben, Giorgio. 2005. States of Exception. Trans. Kevin Attell. Chicago: University of Chicago Press.

Albritton, Rob, Shannon Bell, and Richard Westra, Eds. 2004. New Socialisms: Futures Beyond Globalization. New York: Routledge.

Alphonso, Caroline. 2012. “300-unit YWCA residence opening for low-income women.” The Globe and Mail. May 20. http://www.theglobeandmail.com/news/toronto/300-unit-ywca-residence-openin g-for-low-income-women/article2438836/ (accessed April 10, 2014).

Bannerji, Himani. 2007. "Geography Lessons: On being an Insider/Outsider to the Canadian Nation." Gender Relations in Global Perspective: Essential Readings. Ed. Nancy Cook. Toronto: Canadian Scholars Press: 281-296.

Bannerji, Himani, Linda Carty, Karen Delhi, Susan Heald, and Kate McKenna. 1992. Unsettling Relations: the university as a site of feminist struggles. Boston, MA: South End Press.

Behar, Ruth. 1996. The Vulnerable Observer: Anthropology that Breaks Your Heart. Boston: Beacon Press.

Bhandar, Davina, Richard James Gilmour, Jeet Heer, and Michael CK Ma. 2012. "Too Asian?": Racism, Privilege, and Post-secondary Education. Toronto: Between the Lines.

Bishop, Claire. 2004. “Antagonism and Relational Aesthetics." October Magazine 110 (Fall): 51-79.

Bourriaud, Nicolas. 2002. Relational Aesthetics. Tr. Simon Pleasance and Fronza Woods, Mathieu Copeland. Dijon-Quétigny: les presses du reel.

Brenner, Johanna. 2014. "2 $2{ }^{\text {st }}$ Century Socialist-Feminism." The Journal for the Society of Socialist Studies/Revue de la Sociéte d'études socialistes. 10 (1) Summer: 31-49.

Brenner, Johanna and Nancy Holmstrom, 2012. "Socialist Feminist Strategy Today." Socialist Register 2013: The Question of Strategy, Eds. Leo Panitch, Greg Albo, Vivek Chibber (London: Merlin Press), p. 266-287. 
Castleden, Heather and Theresa Garvin, Huu-ay-aht First Nation. 2008. "Modifying Photovoice for Community-based Participatory Indigenous Research." Social Science and Medicine 66: 1393-1405.

Chandler, Eliza. 2012. “Cripping Community: New Meanings of Disability and Community." NOMOREPOTLUCKS. Issue 19. http://nomorepotlucks.org/site/cripping-community-new-meanings-of-disabilityand-community/ (Accessed January 28, 2015).

Coburn, Elaine. 2014. "Nothing Human is Alien to Me." The Journal for the Society of Socialist Studies/Revue de la Sociéte d'études socialistes. 10 (1) Summer: 1-30.

Davis, Lennard J. 2013. "Introduction: Normality, power and culture.” The Disability Studies Reader. Ed. Lennard J. Davis. New York: Routledge: 1-14.

Dei, George Jerry Sefa, Leeno Luke Karumanchery, and Nisha Karumanchery. 2004. Playing the race card: Exposing white power and privilege. Bern: Peter Lang.

Doughty, Steve. 2011. "YWCA drops the word Christian from its historic name to call itself Platform 51" January 7.

http://www.dailymail.co.uk/news/article-1344779/YWCA-drops-word-Christianhistoric-Platform-51.html (accessed February 17, 2015).

Erevelles, Nirmala. 2011. Disability and Difference in Global Contexts: Enabling a Transformative Body Politic. New York: Palgrave Macmillan.

Ferri, Beth. 2008. "Changing the script: Changing the script: race and disability in Lynn Manning's Weights." International Journal of Inclusive Education 12, nos. 5 - 6: 497509.

Findlay, Stephanie and Nicholas Kohler. 2010. "Too Asian” (renamed "The enrollment controversy") Macleans, November 10, 123(45), 76-81.

Fraser, Nancy. 2012. “Feminism, Capitalism, and the Cunning of History: An Introduction.” Fondation maison des science de l'hommes working paper no. 17, august 2012. Paris. France: 1-14.

Hartmann 1982. "Capitalism, Patriarchy and Job Segregation by Sex." Classes, Power, and 
Conflict. Eds. Anthony Giddens and David Held. Berkeley: University of California Press: 446-469.

Hartmann, Heidi. 1981. "The Unhappy Marriage of Marxism and Feminism: Towards a More Progressive Union." Women and Revolution: A discussion of the Unhappy Marriage of Marxism and Feminism. Ed. Lydia Sargent. Montreal: Black Rose Books: $1-41$.

Hennessey, Rosemary. 2002. "Reclaiming Marxist Feminism for a Need-Based Sexual Politics." The Socialist Feminist Project: A Contemporary Reader in Theory and Politics. Ed. Nancy Holmstrom. New York: Monthly Review Press: 83-89.

Klein, Bonnie. 2008. Excerpt from her address at The Unruly Salon. http://www.unrulysalon.com, accessed August 2013, the url is no longer available.

Lambert, Joe. 2010. The Digital Storytelling Cookbook. San Francisco: Digital Dine Press.

Lambert, Joe. 2013. Digital storytelling: Capturing lives, creating community. New York: Routledge.

LaRocque, Emma. 2011. When the other is me: Native resistance discourse, 1850-1990. Winnipeg, MB: University of Manitoba Press.

Lester-Irabinna, Rigney. 2001. “A First Perspective of Indigenous Australian Participation in Science: Framing Indigenous Research Towards Indigenous Australian Intellectual Sovereignty. Kaurna Higher Education Journal:1-13.

Marx, Karl. 1988 (1844). “Alienated Labour” Marx Selections. Ed. Allen W. Wood. New York: Macmillan Publishing Co: 40-52.

McRuer, Robert. 2006. Crip theory: Cultural signs of queerness and disability. New York: New York University Press.

Meadows L. M., L. E. Lagendyk, W. E. Thurston, A. C. Eisener. 2003. "Balancing Culture, Ethics, and Methods in Qualitative Health Research with Aboriginal Peoples." International Journal of Qualitative Methods. Vol. 2, No. 4: 1-14.

Mitchell, Juliet. 1984. Women: The Longest Revolution. New York: Pantheon Books. 
Mitchell, Juliet. 1974. Psychoanalysis and Feminism. New York: Pantheon Books.

Ng, Roxana. 1993. "A Woman out of Control: Deconstructing Sexism and Racism in the University." Canadian Journal of Education. Vol. 18, No. 3: 189-205.

Oliver, Michael, and Colin Barnes. 2010 [1990]. The New Politics of Disablement. New York: Palgrave Macmillan.

Peck, Janice. 2013. “The 'Oprah Effect:' The Ideological Work of Neoliberalism.” Age of Pop Icons: Exploring Philanthrocapitalism in the Contemporary World. Eds. Gavin Fridell and Martijn Konings. Toronto: University of Toronto Press: 50-71.

Rice, Carla. 2015. "Volatile bodies and vulnerable researchers: The risks of embodiment research.” In S. Batacharya and R. Wong. (Eds.) Embodiment, Pedagogy and Decolonization: Critical and Materialist Considerations. Vancouver: UBC Press.

Rice, Carla, Eliza Chandler, Nadine Changfoot. 2016. "Imagining Otherwise: The Ephemeral Spaces of Envisioning New Meanings." Mobilizing Metaphor: Art, Culture and Disability Activism in Canada. Eds. Christine Kelly and Michael Orsini. Vancouver: University of British Columbia Press.

Rice, Carla. 2014. Becoming Women: The Embodied Self in Image Culture. Toronto, ON: University of Toronto Press.

Roman, Leslie G. 2009a. Disability arts and culture as public pedagogy. International Journal of Inclusive Education, Vol. 13, No. 7, November, 13, 667-675.

Roman, Leslie G. 2009b. Go figure! Public pedagogies, invisible impairments and the performative paradoxes of visibility as veracity. International Journal of Inclusive Education. Vol. 13, No. 7, November, 677-698.

Roman, Leslie G. 1988. Intimacy, labor, and class: ideologies of feminine sexuality in the punk slam dance. In Becoming feminine: The politics of popular culture. Ed. L.G. Roman and L. Christian-Smith. London: Falmer: 143-84.

Roman, Leslie G. and Timothy J. Stanley. 1997. "Chapter 12 Empires, Emigrés and Aliens: Young People's Negotiations of Official and Popular Racism in Canada.” Dangerous Territories: Struggles for Difference and Equality in Education. New York: Routledge: 204-231. 
Roman, Leslie G. and Linda Eyre, Eds. 1997. Dangerous Territories: Struggles for Difference and Equality in Education. New York: Routledge

Russell, Marta, and Ravi Malhotra. 2002. "Capitalism and Disability." Socialist Register 38, no. 38: 211-228.

Sangster, Joan and Meg Luxton, 2012. "Feminism, Co-optation and the Problems of Amnesia: A Response to Nancy Fraser," in Socialist Register 2013: The Question of Strategy, Eds. Leo Panitch, Greg Albo, Vivek Chibber, London: Merlin Press: 288-309.

Sefa Dei, George J., Leeno Luke Karumanchery, and Nisha Karumanchery. 2007. Playing the race card: Exposing white power and privilege. New York: Peter Lang.

Shier, Michael, John R. Graham, and Marion E. Jones. 2009. "Barriers to employment as experienced by disabled people: a qualitative analysis in Calgary and Regina, Canada." Disability and Society v. 24, n. 1 (January): 63-75.

Taylor, Sunny. 2004. “The Right Not to Work: Power and disability.” Monthly Review 55, no. 10. http://www.monthlyreview.org/index.php, accessed September 9, 2013.

Ware, Linda. P. 2002. "A moral conversation on disability: Risking the personal in educational contexts." Hypatia 17, no. 3: 143-72.

Wendell, Susan. 2013. "Unhealthy Disabled: Treating Chronic Illnesses as Disability." The Disability Studies Reader, Fourth Edition. Davis, Lennard J. Ed. New York, NY: Taylor and Francis: 161-176.

Wilson-Kovacs, Dana, Michelle K. Ryan, and Alexander Haslam. 2008. “'Just because you can get a wheelchair in the building doesn't necessarily mean that you can still participate' barriers to the career advancement of disabled professionals." Disability and Society v. 23, n. 7 (December): 705-717.

Wood, Ellen Meiksins. 1995. “A Chronology of the New Left and Its Successors, Or: Who's Old Fashioned Now?," The Socialist Register 1995, London: Merlin Press: 22-49. 